\title{
Main Effects, Epistasis, and Environmental Interactions of Quantitative Trait Loci for Fusarium Head Blight Resistance in a Recombinant Inbred Population
}

\author{
H.-X. Ma, G.-H. Bai, X. Zhang, and W.-Z. Lu
}

First author: Department of Agronomy, Kansas State University, Manhattan 66506; second author: U.S. Department of AgricultureAgricultural Research Service, Plant Science and Entomology Research Unit, Kansas State University, Manhattan 66506; and first, third, and fourth authors: Jiangsu Academy of Agricultural Sciences, Nanjing 210014, China.

Accepted for publication 13 January 2006.

\begin{abstract}
Ma, H.-X., Bai, G.-H., Zhang, X., and Lu, W.-Z. 2006. Main effects, epistasis, and environmental interactions of quantitative trait loci for Fusarium head blight resistance in a recombinant inbred population. Phytopathology 96:534-541.

Chinese Spring Sumai 3 chromosome 7A disomic substitution line (CS-SM3-7ADS) is highly resistant to Fusarium head blight (FHB), and an $\mathrm{F}_{7}$ population of recombinant inbred lines derived from the cross CSSM3-7ADS $\times$ Annong 8455 was evaluated for resistance to FHB to investigate main effects, epistasis, and environmental interactions of quantitative trait loci (QTLs) for FHB resistance. A molecular linkage map consists of 501 simple sequence repeat and amplified fragment length polymorphism markers. A total of 10 QTLs were identified with significant main effects

effect and explained $30.2 \%$ of the phenotypic variance. Susceptible QTLs were detected on chromosomes 1A, 1D, 4A, and 4B. A QTL for enhanced FHB resistance was not detected on chromosome 7A of CS-SM3-7ADS; therefore, the increased FHB resistance in CS-SM3-7ADS was not due to any major FHB-resistance QTL on 7A of Sumai 3, but more likely was due to removal of susceptible alleles of QTLs on 7A of Chinese Spring. QTLMapper detected nine pairs of additive-additive interactions at 17 loci that explained $26 \%$ phenotypic variance. QTL-environment interactions explained $49 \%$ of phenotypic variation, indicating that the environments significantly affected the expression of the QTLs, especially these epistasis QTLs. Adding FHB-enhancing QTLs or removal of susceptible QTLs both may significantly enhance the degree of wheat resistance to FHB in a wheat cultivar.
\end{abstract} on the FHB resistance using MapQTL and QTLMapper software. Among them, CS-SM3-7ADS carries FHB-resistance alleles at five QTLs on chromosomes 2D, 3B, 4D, and 6A. One QTL on 3BS had the largest
Additional keywords: Chinese Spring substitution line.
Fusarium head blight (FHB), primarily caused by Fusarium graminearum Schwabe, is a devastating and insidious disease of wheat in humid and semihumid areas worldwide (4). In China, FHB has affected more than 7 million hectares of wheat, and has caused yield losses of more than 1 million tons in severe epidemics (33). In the United States, several severe FHB outbreaks on wheat and barley from 1991 to 1997 resulted in $\approx \$ 1.3$ billion of direct losses and $\$ 4.8$ billion of losses for the accumulative economic impact (15). FHB has been a threat to wheat production in many other countries. Furthermore, the most serious threat of FHB is from the contamination of harvested grain with mycotoxins that make the grains unsuitable for human consumption and animal fodder (4).

Measures for chemical and agronomic control are either ineffective or infeasible. The employment of FHB-resistant cultivars is still the most economical and effective method to reduce losses caused by FHB (4). Wheat cultivars such as Sumai 3 and Wangshuibai from China, Nobeokabouzu from Japan (4), and Praa 8 and Novokrumka from Europe have been reported to have good

\section{Corresponding author: G.-H. Bai; E-mail address: gbai@ksu.edu}

This article reports the results of research only. Mention of trade names or commercial products in this article is solely for the purpose of providing specific information and does not imply recommendation or endorsement by the U.S. Department of Agriculture.

\section{DOI: $10.1094 /$ PHYTO-96-0534}

This article is in the public domain and not copyrightable. It may be freely reprinted with customary crediting of the source. The American Phytopathological Society, 2006
FHB resistance (11). The quantitative trait loci (QTLs) for FHB resistance recently have been studied extensively in Sumai 3 and its derivatives $(1,2,7,8,31)$. The major QTL on $3 \mathrm{BS}$ of Sumai 3 has been well characterized and used in breeding programs worldwide (4), whereas effects of other QTLs are poorly characterized due to environmental effects on the expression of these QTLs. Characterization of these QTLs different from that on 3BS of Sumai 3 may provide new genes for improvement of FHB resistance in wheat cultivars and could diversify FHB sources of resistance in breeding programs $(10,20,22,34)$. Furthermore, characterization of epistatic interactions between different QTLs and environmental effects on QTL expression may provide new insight into further understanding of genetic mechanisms of FHB resistance and a new strategy for efficient use of limited FHB resistance sources in wheat-breeding programs. In addition, how susceptible QTLs affect FHB expression of a cultivar is still unknown.

Chinese Spring is a cultivar showing moderate reaction to FHB infection, but it became highly resistant when the 7A chromosome of Sumai 3 replaced its corresponding chromosome $(32,35)$. To date, QTL for FHB resistance has not been reported on chromosome 7A of Sumai 3. It is worthwhile to find out whether the increased resistance was from 7A of Sumai 3 or from other chromosomes of Chinese Spring. In the present study, a recombinant inbred line (RIL) population of the cross Chinese Spring Sumai 3 chromosome 7A disomic substitution line (CS-SM37 ADS) $\times$ Annong 8455 was evaluated for FHB resistance in two different environments (greenhouse and field) to determine QTL location, main effects, digenic epistasis, and QTL-environment (QE) interactions. 


\section{MATERIALS AND METHODS}

Plant materials. The CS-SM3-7ADS line was developed by backcrossing chromosome 7A monosomic line of Chinese Spring (recurrent parent as female) to FHB-resistant cultivar Sumai 3 four times (32). After each backcross, progenies with $2 n=41$ chromosomes and morphologically similar to Chinese Spring were selfed to generate a male parent for the next backcross. In $\mathrm{BC}_{4} \mathrm{~F}_{1}$, the monosomic plants were selected and selfed. Disomic plants with $2 n=42$ chromosomes from the selfed progenies were selected and advanced to develop the substitution line CS-SM37ADS. The substitution line was analyzed with a set of chromosome-specific simple sequence repeat (SSR) markers and evaluated for FHB resistance (35). The result showed that CS-SM3-7ADS had all SSR alleles for markers from Chinese Spring, except that markers on chromosome 7A were from Sumai 3. The CS-SM37ADS line showed the same level of resistance as that in Sumai 3 and, therefore, was used as resistant parent in this study. In all, 92 $\mathrm{F}_{7}$ RILs were derived from the cross CS-SM3-7ADS $\times$ Annong 8455 by single-seed descent. Annong 8455 (NPFP $73 \times$ Annong 1) is an FHB-susceptible wheat cultivar released from Anhui Agricultural University in China.

Evaluation of FHB. In 2004, the $\mathrm{F}_{7}$ generation of the RILs and their parents were evaluated in both the United States and China. Plants were grown in a greenhouse at Kansas State University, Manhattan, KS, and in the field of Jiansu Academy of Agricultural Sciences, Nanjing, China. The experiments were arranged as a complete randomized-block design with three replications. In the greenhouse experiment, each replication (pot) consisted of three plants per line, whereas a $1.2-\mathrm{m}$ row was planted as a replication for each line in the field experiment.

F. graminearum isolates GZ 3639 and F15 were used as inocula in Kansas and Nanjing, respectively. They all originated from infected grain harvested from local fields and have been well characterized for their high virulence in wheat. Mung bean liquid medium was used to produce conidial inoculum (3). A droplet of conidia $(\approx 1,000$ spores $)$ was injected into a central floret of selected spikes at anthesis with a hypodermic syringe. In the greenhouse experiment, the inoculated plants were misted with tap water from a hand mister and enclosed in a moist chamber that consisted of a polyethylene-sheet-covered frame on a greenhouse bench. On the fourth day after inoculation, plants were returned to their original positions on the greenhouse benches. In the field experiment, an inoculated spike was covered with a plastic bag for 3 days to maintain high humidity. Scabbed spikelets and the total number of spikelets in each inoculated spike were counted on day 21 after inoculation. Disease severity was calculated as the proportion of scabbed spikelets (PSS) per inoculated spike.

SSR and amplified fragment length polymorphism analysis. In all, 1,013 pairs of SSR primers were used for parental screening, which included 101 GWM SSR primers (19), 432 BARC primers (24), 374 WMC primers (25), 8 GDM primers (18), and 98 CFD or CFA primers $(14,26)$. Polymerase chain reaction $(\mathrm{PCR})$ reactions were performed in a DNA Engine Tetrad Peltier thermal cycler (MJ Research, Waltham, MA). IRdye-labeled M13 primer was used for fragment detection in a Li-Cor DNA Analyzer (Li-Cor, Lincoln, NE). Forward SSR primers were attached with a M13 tail in 5' end. A 10- $\mu$ l PCR mixture for SSR contained $40 \mathrm{ng}$ of template DNA, $0.1 \mu \mathrm{M}$ each primer, $0.2 \mathrm{mM}$ each dNTP, $1 \times$ PCR buffer, $2.5 \mathrm{mM} \mathrm{MgCl}_{2}$, and 0.6 units of Taq polymerase (Promega Corp., Madison, WI). A touchdown program was used for PCR amplification, in which the reaction incubated at $95^{\circ} \mathrm{C}$ for $5 \mathrm{~min}$, then continued for five cycles of $45 \mathrm{~s}$ of denaturing at $95^{\circ} \mathrm{C}$ and $5 \mathrm{~min}$ of annealing at $68^{\circ} \mathrm{C}$, with a decrease of $2^{\circ} \mathrm{C}$ in each subsequent cycle and 1 min of extension at $72^{\circ} \mathrm{C}$. In another five cycles, the annealing temperature started at $58^{\circ} \mathrm{C}$ for $2 \mathrm{~min}$, with a decrease of $2^{\circ} \mathrm{C}$ for subsequent cycles.
Then, PCR went through an additional 25 cycles of $45 \mathrm{~s}$ at $94^{\circ} \mathrm{C}$, $2 \mathrm{~min}$ at $50^{\circ} \mathrm{C}$, and $1 \mathrm{~min}$ at $72^{\circ} \mathrm{C}$, with a final extension at $72^{\circ} \mathrm{C}$ for $5 \mathrm{~min}$.

For amplified fragment length polymorphism (AFLP), the genomic DNA was double digested with PstI and $M s e$ I restriction enzymes and ligated to corresponding AFLP adaptors. A preamplified PCR mixture of $40 \mu \mathrm{l}$ consisted of $1 \times$ PCR buffer, $2.5 \mathrm{mM} \mathrm{MgCl}_{2}, 0.2 \mathrm{mM}$ dNTP mix, $75 \mathrm{ng}$ each of unlabeled PstI (5'-GACTGCGTACATGCAG) and $\mathrm{Mse}$ I (5'-GATGAGTCCTGAGTAA) primers, 0.75 units of Taq Polymerase, and $10 \mu \mathrm{l}$ of 10 -fold diluted temperate DNA. PCR ran for 25 cycles at $94^{\circ} \mathrm{C}$ for $30 \mathrm{~s}, 56^{\circ} \mathrm{C}$ for $1 \mathrm{~min}$, and at $72^{\circ} \mathrm{C}$ for $1 \mathrm{~min}$. The preamplified PCR product then was used as a template for further selective amplification. In all, 112 combinations of MseI and PstI primers were screened between parents for polymorphism. For PCR, a $10-\mu \mathrm{l}$ PCR mixture contained $2 \mu \mathrm{l}$ of 10 -fold diluted preamplified DNA, $1 \times$ PCR buffer, $2.5 \mathrm{mM} \mathrm{MgCl} 2,0.2 \mathrm{mM}$ dNTP mix, $10 \mathrm{ng}$ of unlabeled MseI primer, 0.35 pmol of florescent-labeled Pst $\mathrm{I}$ primer, and 0.2 unit of Taq polymerase. The PCR ran at $94^{\circ} \mathrm{C}$ for $2 \mathrm{~min}$ followed by 13 cycles of $94^{\circ} \mathrm{C}$ for $30 \mathrm{~s}$ and $65^{\circ} \mathrm{C}$ for $30 \mathrm{~s}$, with a touchdown temperature of $-0.7^{\circ} \mathrm{C} /$ cycle in each following cycle, and $72^{\circ} \mathrm{C}$ for $60 \mathrm{~s}$; followed by another 23 cycles at $94^{\circ} \mathrm{C}$ for $30 \mathrm{~s}, 56^{\circ} \mathrm{C}$ for $30 \mathrm{~s}$, and $72^{\circ} \mathrm{C}$ for $60 \mathrm{~s}$. To detect AFLP products, PstI primers were end labeled with IRdye compatible with the Li-Cor DNA analyzer.

The PCR products of SSR or AFLP were mixed with $5 \mu \mathrm{l}$ of formamide loading dye, denatured for $5 \mathrm{~min}$ at $94^{\circ} \mathrm{C}$, and then quickly cooled on ice before loading into a gel. To analyze PCR products in the Li-Cor DNA Analyzer, a gel was made of $20 \mathrm{ml}$ of $6.5 \%$ Gel Matrix (Li-Cor), $75 \mu \mathrm{l}$ of $20 \%$ ammonium persulfate, and $15 \mu \mathrm{l}$ of TEMED by using $25-\mathrm{cm}$ glass plates (Li-Cor). The gel was cast at least $1 \mathrm{~h}$ before use. The gel was pre-run in a $1 \times$ TBE buffer (50 mM Tris, $50 \mathrm{mM}$ boric acid, and $1 \mathrm{mM}$ EDTA) for $15 \mathrm{~min}$ before the samples were loaded. Each well in the gel was loaded with a $0.8-\mu$ l sample. The electrophoresis condition was set at $1,500 \mathrm{~V}, 40 \mathrm{~W}$ at $45^{\circ} \mathrm{C}$. Gel images were collected by a scanner inside the analyzer simultaneously as the electrophoresis progressed and data were scored on a computer screen by visual inspection.

Data analysis. Statistical analysis was performed using the SAS software (SAS Institute, Cary, NC). Effects among genotypes, environments, and replications were estimated by analysis of variance (ANOVA). The heritability was estimated from ANOVA using the formula $h^{2}=\sigma_{G}{ }^{2} /\left(\sigma_{G}{ }^{2}+\left[\sigma_{E}^{2} / r\right]\right)$ for within an environment and the formula $h^{2}=\sigma_{G}^{2} /\left(\sigma_{G}^{2}+\left[\sigma_{G E}{ }^{2} / E\right]+\left[\sigma_{e}^{2} / r E\right]\right)$ for across the environments, where $\sigma_{G}^{2}$ is the genetic variance, $\sigma_{G E}^{2}$ is the variance of genotype-environment interaction, $\sigma_{e}^{2}$ is the residual variance, $E$ is the number of environments, and $r$ is the number of replications. Joinmap 3.0 was used to create a genetic linkage map of SSR and AFLP (29) and MapQTL 5 (28) was used to identify QTL location and effect. The threshold of log of the likelihood ratio value for claiming a significant QTL was determined according to a permutation test with 1,000 runs. Digenic epistasis and environment interaction of QTLs were analyzed using QTLmapper software version 1.6 (30).

\section{RESULTS}

Phenotypic performance of RILs. The FHB severity showed continuous variation among RILs with a major peak toward resistant parent (Fig. 1; Table 1). The averaged PSSs of the individual RILs over two locations ranged from 5.7 to $72 \%$. The PSS of CS-SM3-7ADS was low, $8.9 \%$ in the greenhouse and $13.2 \%$ in the field. Only a few plants showed spread of FHB symptoms from inoculated spikelet to nearby uninoculated spikelets in CSSM3-7ADS under both environments. FHB symptoms on the susceptible parent Annong 8455 spread to from half to entire inoculated spikes in all inoculated plants at both environments. 
Correlation between PSSs of the RILs across two locations was significant $(P<0.01)$, with a correlation coefficient of 0.42 , although the average PSS from the greenhouse experiment was much higher than that from the field experiment. The more severe infection on susceptible genotypes in the greenhouse was due to the fact that greenhouse inoculation provided more favorable conditions for FHB spread within a spike. Significant main effects of QTLs, epistasis between QTLs, and QE interactions were detected by variance analysis (Table 2). Heritability for low PSS was 0.61 over two environments (Table 1).

A genetic map of SSRs and AFLPs. After 917 pairs of SSR and 112 pairs of AFLP primers were screened for polymorphism between parents, 199 SSR and 447 AFLP primers that amplified polymorphic fragments were analyzed in the RIL population. Chinese Spring and Sumai 3 were used as control to verify the chromosome origin of the substitution line using SSR markers. Among 646 markers, 552 were mapped in 41 linkage groups, covering a genetic distance of 2,730 centimorgans (cM). Based on previously published information for known SSR markers in the map $(14,18,19,24-26), 166$ SSR and 335 AFLP markers in 36 linkage groups were tentatively assigned to 21 chromosomes that covered a genetic distance of $2,546 \mathrm{cM}$. The rest of five linkage groups with a total of $184 \mathrm{cM}$ could not be assigned to any chromosome due to lack of linked SSR markers in those linkage groups. For the linkage groups assigned to the chromosomes, the maximum intervals between adjacent markers were less than $31 \mathrm{cM}$ (Table 3). Thirteen chromosomes consisted of at least two linkage groups in the final map. Markers were not evenly distributed over all chromosomes (Table 3). Chromosomes 1B, 2B, $3 \mathrm{~A}, 3 \mathrm{~B}, 3 \mathrm{D}, 4 \mathrm{~A}, 4 \mathrm{~B}, 5 \mathrm{~A}, 5 \mathrm{~B}, 5 \mathrm{D}, 6 \mathrm{~A}, 6 \mathrm{~B}, 7 \mathrm{~B}$, and 7D had a better coverage, with more than $100 \mathrm{cM}$ per chromosome. Chromosome $3 \mathrm{~A}$ had the most markers covering $201 \mathrm{cM}$, whereas chromosome 4D had the fewest markers covering $50 \mathrm{cM}$ of genetic distance.

QTL for FHB resistance. QTLs associated with FHB resistance were identified with composite interval mapping (CIM) based on either PSS of the RILs from each environment or mean PSS over both environments using MapQTL software. Six QTLs were detected on chromosome 1A, 2D, 3B, 4A, 4D, and 6A (Table 4; Fig. 2). Among them, four QTLs showed reduced PSS on chromosomes 2D, 3B, 4D, and 6A of CS-SM3-7ADS, whereas

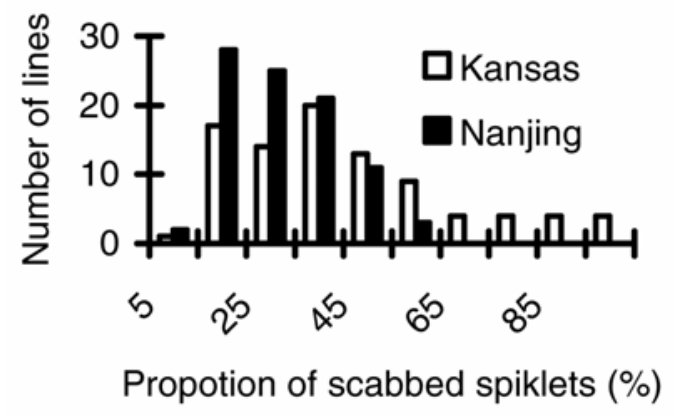

Fig. 1. Frequency distribution of proportion of scabbed spikelets in a spike of wheat recombinant inbred lines derived from the cross CS-SM3-7ADS $\times$ Annong 8455 evaluated in the greenhouse (Kansas) and the field (Nanjing) conditions. the other two showed increased PSS on 1A and 4A of CS-SM37ADS. Haplotype comparison among CS-SM3-7ADS, Chinese Spring, and Sumai 3 indicated that those alleles were from Chinese Spring. The QTL for low PSS on chromosome 3BS showed the largest effect on low PSS in both environments $\left(R^{2}=\right.$ $26.7 \%$ in the greenhouse and $R^{2}=17.2 \%$ in the field), and was positioned in the 9-cM interval between Xgwm533 and Xgwm493. A QTL on 1A was also significant in both locations and explained $9.9 \%$ of phenotypic variation over two environments. A QTL on $2 \mathrm{D}$ was mapped in two different positions of the chromosome when the data from two environments were analyzed. This QTL explained 13.6 and $10.6 \%$ of the phenotypic variance in the greenhouse and the field, respectively. When the mean PSS from both environments were analyzed, the significant QTL matched with the one identified in the greenhouse environment. Another three QTLs were significant when mean PSS from two environments was analyzed, but only QTLs on 4A and 4D were significant at one environment.

When data were analyzed using QTLmapper software, seven putative QTLs with a significant main effect on FHB resistance

TABLE 2. Analysis of variance for the proportion of scabbed spikelets (PSS) in a wheat spike from recombinant inbred line (RIL) population evaluated in greenhouse (Kansas) and field (Nanjing) conditions

\begin{tabular}{lrcrc}
\hline Item & df & MS & $F$ value & $P>\mathrm{F}$ \\
\hline Genotype & 91 & $1,395.67$ & 7.14 & $<0.0001$ \\
Environment & 1 & $29,489.21$ & 150.78 & $<0.0001$ \\
Genotype $\times$ environment & 91 & 687.0235 & 3.51 & $<0.0001$ \\
Replication & 2 & $4,032.10$ & 20.62 & $<0.0001$ \\
Error & 367 & 195.58 & $\ldots$ & $\ldots$ \\
\hline
\end{tabular}

TABLE 3. Number of mapped markers and total genetic distance in each wheat chromosome based on the genetic map developed from the recombinant inbred line population derived from the wheat cross Chinese Spring Sumai 3 chromosome 7A disomic substitution line $\times$ Annong 8455

\begin{tabular}{|c|c|c|c|}
\hline Chromosome & $\begin{array}{l}\text { Mapped } \\
\text { markers }\end{array}$ & $\begin{array}{c}\text { Length of } \\
\text { linkage group }\end{array}$ & $\begin{array}{l}\text { Maxima } \\
\text { interval }^{\mathrm{a}}\end{array}$ \\
\hline $1 \mathrm{~A}$ & 23 & 90 & 14 \\
\hline $1 \mathrm{~B}$ & 24 & 178 & 18 \\
\hline $1 \mathrm{D}$ & 14 & 53 & 11 \\
\hline $2 \mathrm{~A}$ & 16 & 91 & 25 \\
\hline 2B & 30 & 131 & 18 \\
\hline $2 \mathrm{D}$ & 24 & 81 & 14 \\
\hline $3 \mathrm{~A}$ & 38 & 201 & 26 \\
\hline $3 B$ & 27 & 111 & 20 \\
\hline $3 \mathrm{D}$ & 17 & 139 & 28 \\
\hline $4 \mathrm{~A}$ & 37 & 150 & 14 \\
\hline $4 B$ & 21 & 124 & 13 \\
\hline $4 \mathrm{D}$ & 9 & 52 & 12 \\
\hline $5 \mathrm{~A}$ & 30 & 141 & 16 \\
\hline $5 B$ & 33 & 150 & 16 \\
\hline $5 \mathrm{D}$ & 14 & 106 & 31 \\
\hline $6 \mathrm{~A}$ & 31 & 135 & 23 \\
\hline $6 \mathrm{~B}$ & 28 & 138 & 11 \\
\hline $6 \mathrm{D}$ & 9 & 92 & 19 \\
\hline 7A & 13 & 70 & 12 \\
\hline $7 \mathrm{~B}$ & 48 & 171 & 15 \\
\hline $7 \mathrm{D}$ & 15 & 142 & 23 \\
\hline
\end{tabular}

a Maximum genetic distance between two adjacent markers.

TABLE 1. Descriptive statistics of the proportion of scabbed spikelets (PSS) in a wheat spike from the parents and their recombinant inbred line (RIL) population evaluated in greenhouse (Kansas) and field (Nanjing) conditions

\begin{tabular}{lccccc}
\hline & \multicolumn{3}{c}{ PSS (\%) } \\
\cline { 2 - 5 } Environment & CS-SM3-7ADS $^{\mathrm{a}}$ & Annong 8455 & RIL means & RIL range & \multicolumn{1}{c}{$h^{2}$} \\
\hline Greenhouse & 8.9 & 97.9 & 37.0 & $6.0-100.0$ \\
Field & 13.2 & 45.1 & 22.2 & $4.1-55.0$ & 0.84 \\
Mean & 11.0 & 71.5 & 29.6 & $5.7-72.2$ & 0.65 \\
\hline
\end{tabular}

${ }^{a}$ Chinese Spring Sumai 3 chromosome 7A disomic substitution line. 
were detected on chromosome 1A, 1D, 3B, 4B, and 4D (Table 5; Fig. 2). They collectively explained $24.8 \%$ of the phenotypic variation for the main effect. Alleles at two 3B QTLs and a 4D QTL demonstrated reduced PSS in CS-SM3-7ADS, whereas the alleles at other QTLs showed increased PSS in CS-SM3-7ADS. Both MapQTL and QTLMapper software detected three QTLs in common on chromosomes 1A, 3B, and 4D. Another seven QTLs were detected by only one of the two software.

Epistasis and $\mathbf{Q E}$ interaction. Interactions were detected between nine pairs of QTLs for FHB resistance, which involved 17 QTLs on 10 chromosomes (Table 5; Fig. 2). Those digenic interactions together accounted for $26.5 \%$ of the phenotypic variation. Among them, three digenic interactions between $5 \mathrm{~A}$ and 1D, 4D and 7B, and 4B and 3B had one QTL in each pair with a significant main effect on FHB resistance that interacted with another QTL without the main effect. Another six pairs of digenic interactions occurred between those QTLs with no significant main effect on FHB resistance (Table 5). Three pairs of digenic interactions (3B and $1 \mathrm{~B}, 4 \mathrm{D}$ and $7 \mathrm{~B}$, and $5 \mathrm{~A}$ and $1 \mathrm{D}$ ) facilitated increased PSS, whereas another six pairs tended to reduce PSS. The results indicate that additive-additive (AA) epistatic interactions play an important role in performance of FHB resistance in CS-SM3-7ADS.

QE interactions were detected at eight loci that, together, explained $16.98 \%$ of phenotypic variation. Those QTLs were located on chromosome 1D, 2A, 2B, 3B, 4B, 5A, and 6D. Most of them showed increased PSS $\left(h^{2} \mathrm{ae}=9.7 \%\right)$ and only three of them showed reduced PSS in the greenhouse environment $\left(h^{2} \mathrm{ae}=\right.$ $7.0 \%$ ) (Table 5). The largest environmental effect was detected on 1D QTL in the interval Xbarc149-Xwmc222 $\left(h^{2} \mathrm{ae}_{\mathrm{j}}=5.7 \%\right)$ (Table $5)$. Nine pairs of interactions were detected for additive-additiveenvironment (AAE), which explained $32.55 \%$ of phenotypic variation and involved 18 loci on $1 \mathrm{~A}, 1 \mathrm{~B}, 1 \mathrm{D}, 2 \mathrm{~A}, 3 \mathrm{~A}, 3 \mathrm{~B}, 4 \mathrm{~A}$, 4B, 4D, 5A, 6D, and 7B. Four AAE interactions showed reduced PSS in the greenhouse conditions, which explained $\approx 15 \%$ of phenotypic variation, whereas five AAE interactions showed increased PSS in the greenhouse conditions and explained $18 \%$ of phenotypic variation.

\section{DISCUSSION}

Schroeder and Christensen (21) proposed two types of resistance in wheat: resistance to initial infection (type I) and resistance to spread of blight symptoms within a spike (type II). Resistance to spread of FHB symptoms within a spike has been considered to be a major component of FHB resistance (5). Single-floret inoculation commonly has been accepted as a standard method for measuring type II resistance. Two typical environments usually are used for measuring type II resistance: greenhouse and field. In this study, the RIL population and their parents were evaluated for FHB resistance in both greenhouse (Kansas) and field (Nanjing, China) environments to demonstrate how environments affect QTL expression of type II FHB resis- tance. The result showed that difference in PSS between RILs with extreme reactions to FHB from the field experiment $(51 \%)$ was much smaller than that from the greenhouse experiment $(96 \%)$. This result indicated that greenhouse conditions are more favorable for FHB spread in susceptible genotype and provide better separation between different genotypes. However, significant correlation was observed between the data from two environments and QTLs with large effect were consistently detected in the same chromosomes using the data from two environments. In addition, CS-SM3-7ADS showed as high FHB resistance as Sumai 3, whereas Annong 8455 showed high PSS in both environments. The result agrees with previous reports $(32,35)$. Therefore, both disease evaluation conditions were suitable for this study.

QTL mapping and cytogenetics studies associated FHB resistance with most of the wheat chromosomes (4). Creating substitution lines by replacing one chromosome in a susceptible cultivar with a corresponding chromosome from a resistant cultivar provides a useful tool to test the resistance effect of an individual chromosome. Using this method, a set of 21 Chinese Spring substitution lines with Sumai 3 as the chromosome donor was developed and evaluated for FHB resistance. Surprisingly, the substitution line CS-SM3-7ADS demonstrated the same high level of resistance as donor parent Sumai $3(32,35)$. Interestingly, chromosome 7A has not been documented to have any FHBresistance QTL to date, although QTLs for FHB resistance have been mapped extensively in Sumai 3 and its derivatives. In this study, neither main effect QTL nor epistatic QTL was identified on chromosome 7A from Sumai 3. This result suggests that chromosome 7A of Sumai 3 may not carry any QTL for FHB resistance. The increased resistance in CS-SM3-7ADS might result from replacement of a susceptible gene or a suppressor gene on chromosome 7A of Chinese Spring by a neutral allele from Sumai 3. Investigation of FHB reaction of ditelosomic lines or nullitetrosomic lines may help further determination of the effect of Chinese Spring 7A chromosome on FHB resistance.

Grausgruber et al. (12) investigated a series of substitution lines of Chinese Spring replaced by single chromosomes from Cheyenne (susceptible parent) and reported that 3B of Chinese Spring was associated with FHB resistance. The same conclusion was obtained through the molecular mapping approach in this study. Marker data in this study suggested that the QTL from CSSM3-7ADS was located in the distal end of chromosome 3BS, as reported in Ning 7840 (36). However, the QTL in CS-SM3-7ADS had a smaller effect on FHB resistance than that from Sumai 3 or Ning $7840(1,36)$, and banding patterns of linked SSR markers also were different from that in Sumai 3, suggesting that the 3BS QTL in CS-SM3-7ADS is most likely allelic to the 3BS QTL in Sumai 3. Similar QTLs on 3BS with smaller effects than Sumai 3 also were reported from other Chinese sources, such as Wangshuibai (34), Ning 894037 (23), and Huapei 57-2 (6). This result suggests that the 3BS QTL may be a conserved region for major FHB resistance QTL. Several alleles with various levels of FHB resistance in this region exist in different Chinese landraces. In

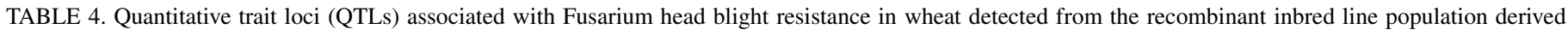
from the cross Chinese Spring Sumai 3 chromosome 7A disomic substitution line $\times$ Annong 8455 by composite interval mapping using MapQTL

\begin{tabular}{|c|c|c|c|c|c|c|c|c|c|c|}
\hline \multirow[b]{2}{*}{ Chromosome } & \multirow[b]{2}{*}{ Flanking markers } & \multicolumn{3}{|c|}{ Kansas } & \multicolumn{3}{|c|}{ Jiangsu } & \multicolumn{3}{|c|}{ Mean over two environments } \\
\hline & & LOD & $R^{2}$ & Add. & LOD & $R^{2}$ & Add. & LOD & $R^{2}$ & Add. \\
\hline $1 \mathrm{~A}$ & XmGTG.pAG225-Xbarc28 & $1.85^{*}$ & 9 & 7.03 & $2.03 *$ & 10.5 & 4.24 & $2.05^{*}$ & 9.9 & 4.81 \\
\hline \multirow[t]{2}{*}{$2 \mathrm{D}$} & ХmCGTA.pACT236-ХmACAG.pACT134 & $2.86 * *$ & 13.6 & -9.11 & $\ldots$ & $\ldots$ & $\ldots$ & $3.47 * *$ & 11.8 & -6.5 \\
\hline & ХmCGAC.pTGC102-XmTGC.pTGC70 & $\ldots$ & $\ldots$ & $\ldots$ & $2.19 *$ & 10.6 & -4.04 & $\ldots$ & $\cdots$ & \\
\hline $3 B$ & Xgwm533-Xgwm493 & $4.8 * *$ & 26.7 & -13.89 & $3.09 * *$ & 17.2 & -5.8 & $5.71 * *$ & 30.2 & -9.62 \\
\hline $4 \mathrm{~A}$ & mGCG.pGTG223-Xwmc617.2 & $1.9 *$ & 12.3 & 9.33 & $\ldots$ & $\ldots$ & $\ldots$ & $1.96^{*}$ & 9.3 & 6.71 \\
\hline 4D & Xcfd84-Xwmc331 & $\ldots$ & $\ldots$ & $\ldots$ & $1.89 *$ & 9.2 & -3.85 & $2.13 *$ & 10.8 & -5.43 \\
\hline $6 \mathrm{~A}$ & ХmCTG.pACTG134-XmCTG.pACT132 & $\ldots$ & $\ldots$ & $\ldots$ & $\ldots$ & $\ldots$ & $\ldots$ & $1.83 *$ & 8.9 & -5.06 \\
\hline
\end{tabular}

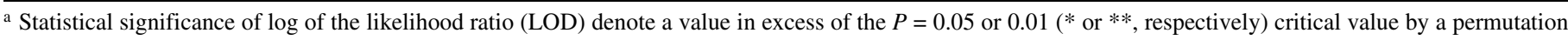
test with 1,000 permutations. 
this study, two different softwares consistently detected the major QTL in CS-SM3-7ADS in two environments. The digenic interaction of this QTL with other QTLs was not detected and its interaction with environment showed increased FHB resistance under the favorable FHB infection condition (greenhouse). The results suggest that this QTL is a stable major QTL for FHB resistance and exists in many FHB-resistant sources. Because many Chinese Spring genetic stocks are available, they can be used as useful tools for molecular cloning of 3BS QTL for FHB resistance.
QTLMapper detected an additional QTL on chromosome 3B, which agrees with a previous report by Somers et al. (25). This QTL is a minor QTL for low PSS and also expressed as an epistatic QTL to interact with a QTL on $4 \mathrm{~B}$ and with environments (AAE) to enhance FHB resistance. Both softwares detected a QTL on 4D that showed increased FHB resistance in CS-SM37ADS, but epistatic interaction with a QTL on 7B and the environment showed reduced FHB resistance. MapQTL detected an additional QTL for lower PSS on 2D when PSS from the greenhouse experiment and mean PSS over two experiments were
$1 \mathrm{~A}$

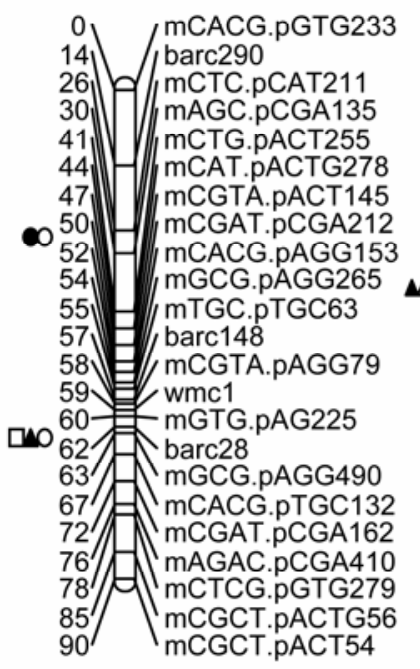

1B

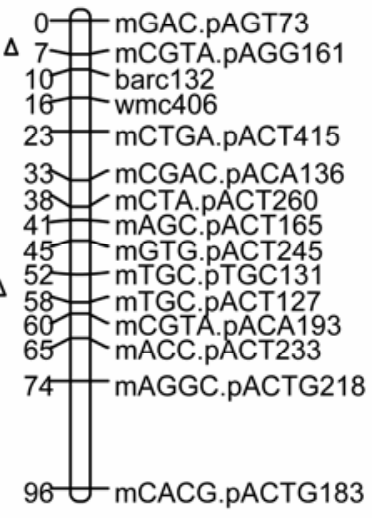

$1 \mathrm{D}$

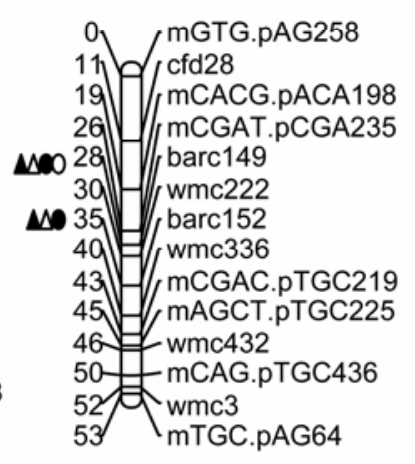

$2 \mathrm{~A}$

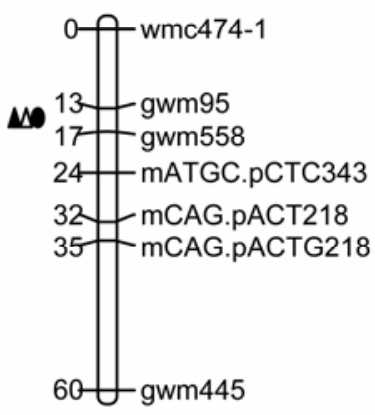

2B

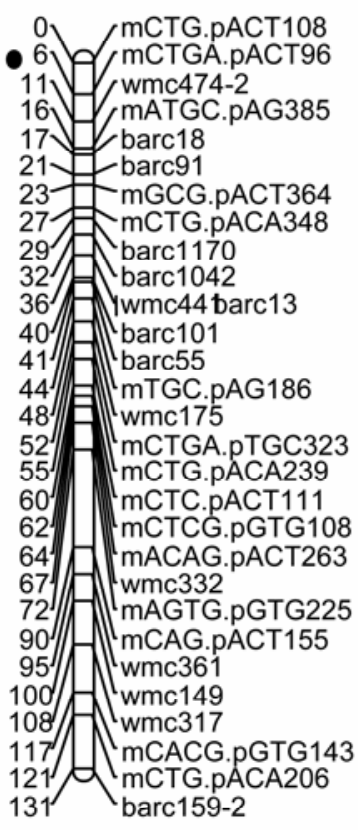

$2 \mathrm{D}$

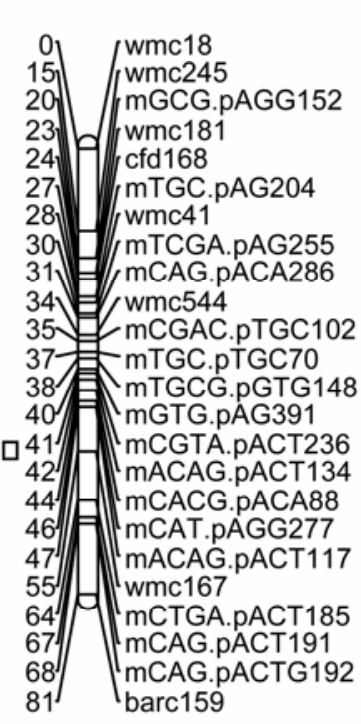

3B

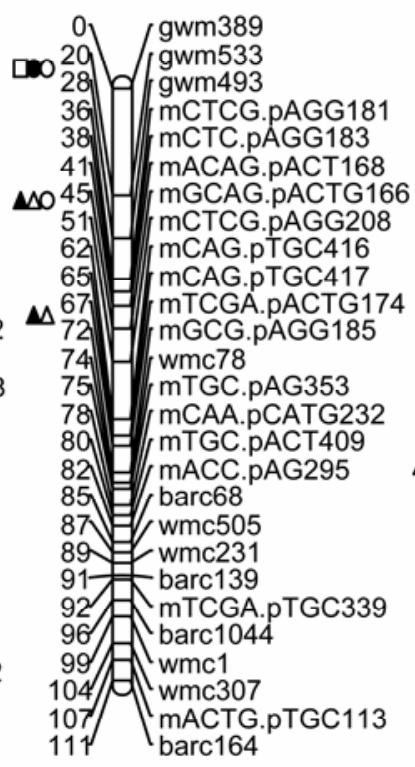

$4 \mathrm{~A}$

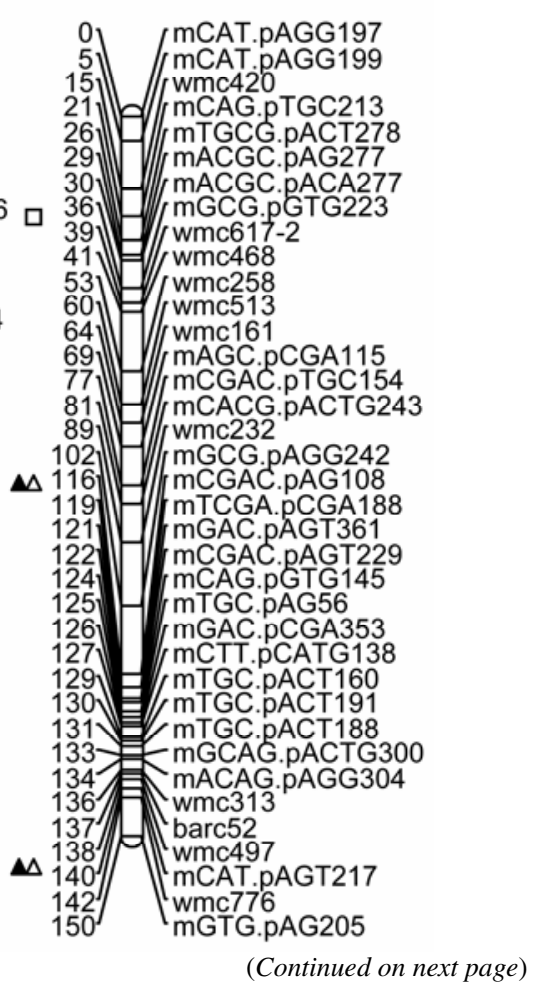

Fig. 2. Portion of genetic linkage map constructed from $\mathrm{F}_{7}$ wheat recombinant inbred lines derived from the wheat cross CS-SM3-7ADS $\times$ Annong 8455 showing chromosome positions of main effect quantitative trait loci (QTLs), epistatic QTLs, and the QTLs involved in QTL-environment (QE) interactions for Fusarium head blight resistance in wheat. QTL detected by MapQTL ( $\square$ ), additive (A) effect QTL detected by QTLmapper (O), QTL with additive-additive (AA) epistasis $(\Delta)$, QTL with additive-environment $(\mathrm{AE})$ interactions $(\bullet)$, and QTL with AA epistasis-environment (AAE) interactions $(\mathbf{\Delta})$. 
analyzed. Yao et al. (32) and Zhou et al. (35) reported that the Chinese Spring-Sumai 3 chromosome 2D substitution line was more susceptible than Chinese Spring, and postulated that the chromosome 2D of Sumai 3 might have a gene for FHB susceptibility. Our result suggests that Chinese Spring may carry an FHB resistance allele on 2D. The reduced FHB resistance in the Chinese Spring Sumai 3 chromosome 2D substitution line likely was due to replacement of FHB resistance allele on 2D of Chinese Spring by a neutral allele or susceptible allele on 2D of Sumai 3.

The study also identified susceptible alleles at five QTLs on chromosomes 1A, 1D, 4A, and 4B. Among them, both softwares consistently detected one QTL on 1A at interval XmGTG.pAG225$X$ barc 28 in two environments. Although it had a minor effect, it

Fig. 2. (Continued from preceding page)

$4 \mathrm{~B}$

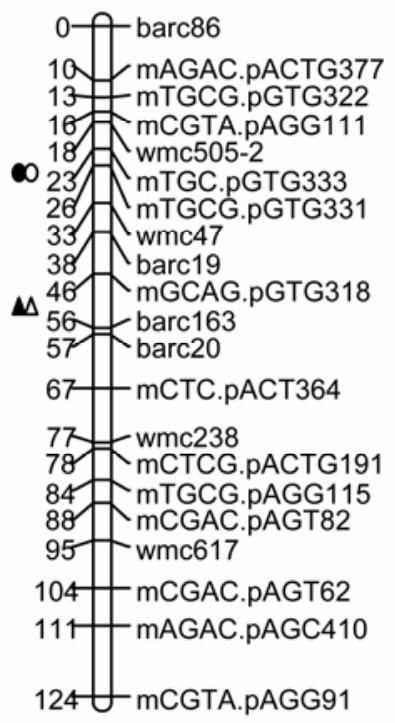

4D

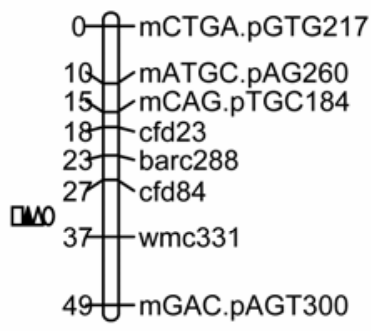

$6 \mathrm{D}$

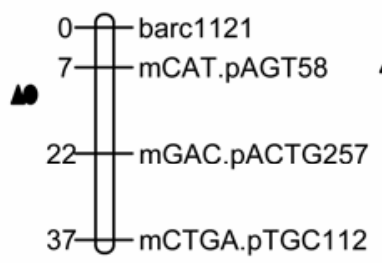

7B

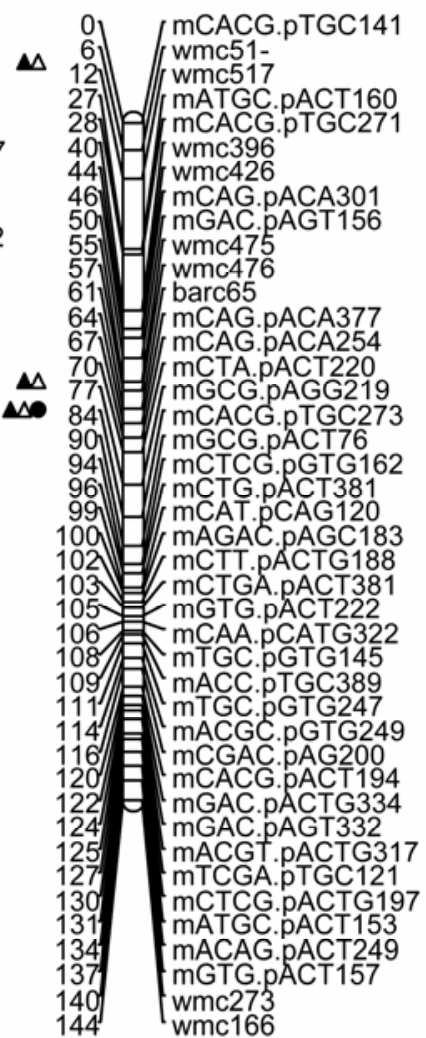

$5 \mathrm{~A}$

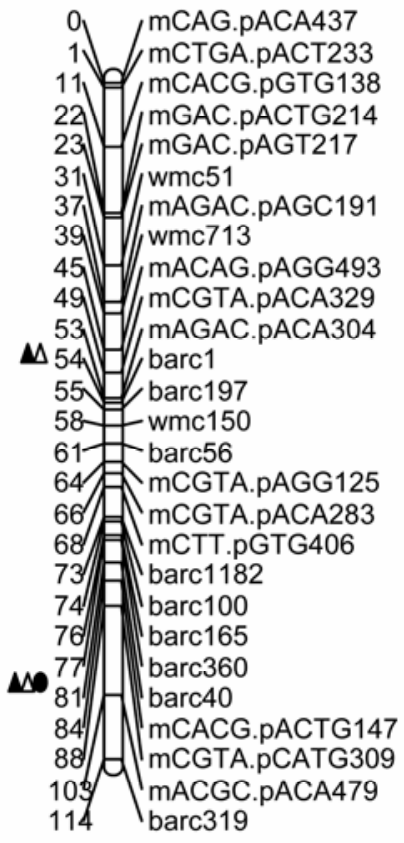

$6 \mathrm{~A}$

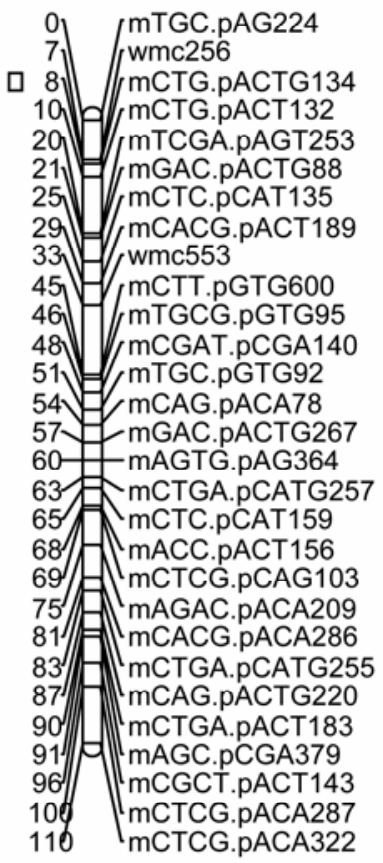


appeared to be stable for increased PSS and didn't interact with the environments. A QTL for increased PSS was detected on 1D only by QTLmapper, mainly through significant interaction with a QTL on 5A and environments. QTLs on 4A and 4B were detected by only one software and showed minor effects on increased PSS. These may be unstable QTLs for increased PSS. Removal of these susceptible QTLs should improve the level of resistance in wheat cultivars.

The mapping population of 92 RILs might underestimate the number of QTLs in this study. Vales et al. (27) reported that more minor QTLs might be detected when a population size was increased. However, they did not detect spurious QTL for barley stripe rust resistance even when the population size was reduced to 50 lines in comparison with a large population of 408 lines (27). In addition, the QTLs estimated by different software were different in this study. This may be due to different software programs using different techniques for detection and estimation of QTL (27). However, QTLs with a major effect on FHB resistance were detected by both softwares. Those discrepant QTLs detected by different software usually showed a minor effect on FHB resistance and associated with a large environmental effect. Therefore, selection for FHB resistance in breeding programs should focus on the major QTL.

The heritable genetic components include main effect and AA epistasis. These two components were statistically separated by the two-locus analysis in the present study. The analysis resolved nine pairs of AA interactions involving 17 different loci that explained $26 \%$ of phenotypic variation, whereas only 7 QTLs, identified as main effect QTLs, explained $\approx 24.8 \%$ phenotypic variation. This indicates that genetic effect of AA epistasis is equally important as that of QTL main effect, and AA epistasis plays an important role in FHB resistance. Epistatic effects also were noticed in a classic genetic study (5). Using molecular mapping, Gervais et al. (10) and Zhou et al. (36), using two-way marker analysis, identified AA epistatic effects for resistance to FHB. The results indicated that wheat FHB resistance is a complicated trait and may be controlled by a complicated gene network.
Epistatic interactions between minor QTLs may play a significant role in enhancing overall FHB resistance in a cultivar. Therefore, to select a cultivar with a high level of resistance, breeders need to select for all FHB-enhancing genes and remove as many susceptible genes as possible in the cultivar. In addition, manipulating resistance genes in moderately resistant cultivars may make efficient use of limited genetic resources and provide a new approach for quick release of commercial cultivars.

Environments can significantly affect the level of FHB resistance in a cultivar. As seen in this study, the PSS for Annong 8455 was $55 \%$ in field conditions but almost $100 \%$ in greenhouse conditions. Many studies have demonstrated the significance of genotype-environment interactions and used it to determine the stability of FHB resistance by analyzing data from multiple years or locations $(9,13,16)$. QTL mapping for FHB resistance provided the information on possible QTLs that behaved differently under different environments by simple comparison of the QTLs detected in different years and locations $(10,17,25)$. However, such comparison could not provide direct estimates of the interaction effects of QTLs with the environment. Yang et al. (31) attempted to separate relative contributions of QE interactions and didn't detect significant interactions between main effect or epistatic QTLs and the environments. The results in this study revealed that environments affected most QTLs with a main effect on PSS (Table 5). In general, if main effect showed increased resistance, their interaction with the environment also resulted in increased resistance under favorable infection conditions. The result indicates that the same locus may express different degrees of resistance in different environments. In addition, although the main effect of some QTLs is not significant in QTL analysis, they might show a significant interaction with environments and play an important role in overall FHB resistance performance. Those "epistatic QTLs" were more sensitive to the change of environments. Furthermore, a very large portion of phenotypic variation $(32.5 \%)$ was explained by interactions between AA epistasis and environments. This indicates that the environment mainly interacted with digenic epistatic QTLs to alter QTL effects on FHB

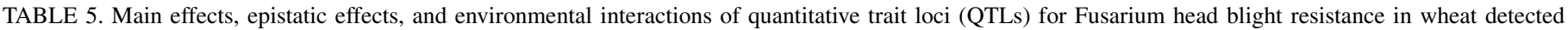

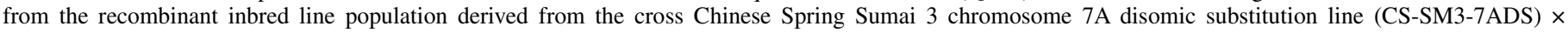
Annong 8455 using QTLMapper software ${ }^{\mathrm{a}}$

\begin{tabular}{|c|c|c|c|c|c|c|c|c|c|c|c|c|c|c|c|c|}
\hline Chr. & Flanking markers (i) & Chr. & Flanking markers (j) & LR & $\mathrm{a}_{\mathrm{i}}$ & $h^{2} \mathrm{a}_{\mathrm{i}}$ & $a_{j}$ & $h^{2} \mathrm{a}_{\mathrm{j}}$ & $\mathrm{aa}_{\mathrm{ij}}$ & $h^{2} \mathrm{aa}_{\mathrm{ij}}$ & $\mathrm{ae}_{\mathrm{i}}$ & $h^{2} \mathrm{ae}_{\mathrm{i}}$ & $\mathrm{ae}_{\mathrm{j}}$ & $h^{2} \mathrm{ae}_{\mathrm{j}}$ & $\mathrm{aae}_{\mathrm{ij}}$ & $h^{2} \mathrm{aae}_{\mathrm{ij}}$ \\
\hline $1 \mathrm{~A}$ & $\begin{array}{c}X m C G A T \cdot p C G A 212- \\
\text { XmCACG.pAGG153 }\end{array}$ & $4 \mathrm{~B}$ & $\begin{array}{l}X w m c 505.2- \\
X m T G C p G T G 333\end{array}$ & 19.20 & 2.90 & 1.50 & 2.54 & 1.15 & $\ldots$ & $\ldots$ & $\ldots$ & $\ldots$ & 1.91 & 1.31 & $\ldots$ & $\ldots$ \\
\hline $1 \mathrm{~A}$ & $\begin{array}{l}\text { XmGTG.pAG225- } \\
\quad \text { Xbarc } 28\end{array}$ & $6 \mathrm{D}$ & $\begin{array}{l}\text { XmCAT.pAGT58- } \\
\text { XmGAC.pACTG257 }\end{array}$ & 39.05 & 2.66 & 2.81 & $\ldots$ & $\cdots$ & $\ldots$ & $\ldots$ & $\ldots$ & $\ldots$ & 1.20 & 0.51 & 1.34 & 0.64 \\
\hline $\begin{array}{l}2 \mathrm{~A} \\
3 \mathrm{~A}\end{array}$ & $\begin{array}{l}\text { Xgwm95-Xgwm558 } \\
\text { XmCAG.pACA262- }\end{array}$ & $1 \mathrm{D}$ & Xwmc222-Xbarc152 & 43.58 & $\ldots$ & $\ldots$ & $\ldots$ & $\cdots$ & -5.83 & 6.07 & 2.13 & 1.59 & 1.27 & 0.57 & -1.53 & 0.81 \\
\hline $3 B$ & $\begin{array}{c}\text { ХmCGTA.pACT280 } \\
\text { XmTCGA.pACTG174- }\end{array}$ & $7 \mathrm{~B}$ & $\begin{array}{l}\text { Xwmc51.1-Xwmc517 } \\
\text { XmTGC.pTGC131- }\end{array}$ & 25.97 & $\cdots$ & $\cdots$ & $\cdots$ & $\cdots$ & -3.71 & 2.46 & $\cdots$ & $\cdots$ & $\ldots$ & $\cdots$ & -3.21 & 3.46 \\
\hline $3 \mathrm{~B}$ & $\begin{array}{c}X m G C G . p A G G 185 \\
\text { Xgwm533-Xgwm493 }\end{array}$ & $\begin{array}{l}1 \mathrm{~B} \\
2 \mathrm{~B}\end{array}$ & $\begin{array}{c}\text { XmTGC.pACT127 } \\
\text { XmCTGA.pACT96- }\end{array}$ & 54.55 & $\ldots$ & $\cdots$ & $\cdots$ & $\ldots$ & 5.12 & 4.68 & $\ldots$ & $\ldots$ & $\cdots$ & $\cdots$ & 4.80 & 8.04 \\
\hline $4 \mathrm{~A}$ & Xwmc497- & & $\begin{array}{l}\text { Хwmc474.2 } \\
\text { ХmCTA.pACT220- }\end{array}$ & 74.08 & -8.18 & 11.95 & $\ldots$ & $\ldots$ & $\ldots$ & $\ldots$ & -2.58 & 2.28 & -1.36 & 0.65 & $\ldots$ & $\cdots$ \\
\hline $4 \mathrm{~B}$ & $\begin{array}{l}X m C A T . p A G T 217 \\
X m G C A G . p G T G 318-\end{array}$ & $7 \mathrm{~B}$ & $\begin{array}{r}X m G C G . p A G G 219 \\
X m G C A G . p A C T 166-\end{array}$ & 21.11 & $\ldots$ & $\ldots$ & $\ldots$ & $\ldots$ & -2.86 & 1.46 & $\ldots$ & $\cdots$ & $\cdots$ & $\ldots$ & -4.52 & 4.14 \\
\hline $4 \mathrm{D}$ & $\begin{array}{l}\text { Xbarc163 } \\
\text { Xcfd84-Xwmc331 }\end{array}$ & 3B & $\begin{array}{l}\text { XmCTCG.pAGG208 } \\
\text { XmGCG.pAGG219- }\end{array}$ & 58.50 & $\ldots$ & $\ldots$ & -2.29 & 0.94 & -4.41 & 3.47 & $\cdots$ & $\cdots$ & $\cdots$ & $\cdots$ & -3.79 & 5.79 \\
\hline & & $7 \mathrm{~B}$ & XmCACG.pTGC273 & 35.48 & -2.69 & 1.29 & $\cdots$ & $\cdots$ & 2.61 & 1.22 & $\cdots$ & $\cdots$ & $\cdots$ & $\ldots$ & 1.80 & 1.17 \\
\hline $5 \mathrm{~A}$ & Xbarc $360-X b a r c 40$ & $1 \mathrm{D}$ & Xbarc149-Xwmc222 & 59.25 & $\ldots$ & $\ldots$ & 5.06 & 4.58 & 3.26 & 1.90 & -3.28 & 4.11 & 4.06 & 5.71 & 5.13 & 7.07 \\
\hline $5 \mathrm{~A}$ & $\begin{array}{l}\text { ХmAGACpACA304- } \\
\text { Xbarc1 }\end{array}$ & $4 \mathrm{~A}$ & $\begin{array}{l}\text { XmCGAC.pAG108- } \\
\text { XmTCGA.pCGA188 }\end{array}$ & 19.06 & $\ldots$ & $\ldots$ & $\ldots$ & $\ldots$ & -2.54 & 1.15 & $\ldots$ & $\cdots$ & $\ldots$ & $\cdots$ & 2.10 & 1.42 \\
\hline $7 \mathrm{~B}$ & Хwmc51.1-Хwmc517 & $1 \mathrm{~B}$ & $\begin{array}{l}\text { XmGAC.pAGT73- } \\
\text { XmCGTA.pAGG161 }\end{array}$ & 21.50 & $\ldots$ & $\ldots$ & $\ldots$ & $\ldots$ & -4.79 & 4.09 & $\ldots$ & $\ldots$ & $\ldots$ & $\cdots$ & $\ldots$ & $\ldots$ \\
\hline
\end{tabular}

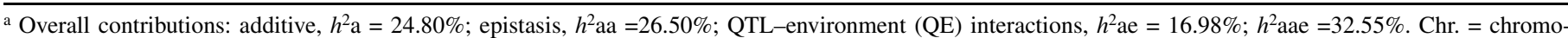
some. $\mathrm{a}_{\mathrm{i}}$ and $\mathrm{a}_{\mathrm{j}}$ are the additive effects of testing loci $\mathrm{i}$ and $\mathrm{j}$, respectively; a positive value indicates the CS-SM3-7ADS genotype having a positive effect on proportion of scabbed spikelets (PSS). a $\mathrm{a}_{\mathrm{ij}}$ is the effect of additive by additive interaction between two loci $\mathrm{i}$ and $\mathrm{j}$; a positive value indicates that the parental twolocus combinations have a positive effect on PSS $\mathrm{ae}_{\mathrm{i}}$, $\mathrm{ae}_{\mathrm{j}}$, and $\mathrm{ae}_{\mathrm{ij}}$ are the additive effects of the QE interactions from single loci $\mathrm{i}$ and $\mathrm{j}$ and epistatic loci, respectively; a positive value indicates that the Kansas environment has a positive effect on PSS. $h^{2} \mathrm{a}_{\mathrm{i}}, h^{2} \mathrm{a}_{\mathrm{j}}, h^{2} \mathrm{aa}_{\mathrm{ij}}, h^{2} \mathrm{ae}_{\mathrm{i}}, h^{2} \mathrm{ae}_{\mathrm{j}}$, and $h^{2} \mathrm{aae}_{\mathrm{ij}}$ are the percentages of the phenotypic variations explained by $\mathrm{a}_{\mathrm{i}}, \mathrm{a}_{\mathrm{i}}, \mathrm{aa}_{\mathrm{ij}}, \mathrm{ae}_{\mathrm{i}}, \mathrm{ae}_{\mathrm{i}}$, and $\mathrm{aae}_{\mathrm{ij}}$, respectively. 
resistance. The interaction usually enhances the AA epistatic effect, with only one exception. More than half of such interactions showed increased PSS in the greenhouse environment. Therefore, AAE plays a more important role in FHB resistance expression than main QTL effect or AA epitasis alone. Therefore, creating appropriate environments for FHB evaluation is very important for genetic research and breeding selection.

\section{ACKNOWLEDGMENTS}

This project was partly supported by the United States Wheat and Barley Scab Initiative, the International Cooperative Project (2004DFA01100), and "863" program (2001AA211021, 2002AA207003) of China. This is contribution no. 05-336-J of the Kansas Agricultural Experiment Station, Manhattan

\section{LITERATURE CITED}

1. Anderson, J. A., Stack, R. W., Liu, S., Waldron, B. L., Fjeld, A. D., Coyne, C., Moreno-Sevilla, B., Mitchell Fetch, J., Song, Q. J., Cregan, P. B., and Frohberg, R. C. 2001. DNA markers for Fusarium head blight resistance QTLs in two wheat populations. Theor. Appl. Genet. 102:11641168 .

2. Bai, G. H., Kolb, F. L., Shaner, G. E., and Domier, L. L. 1999. Amplified fragment length polymorphism markers linked to a major quantitative trait locus controlling scab resistance in wheat. Phytopathology 89:343-348.

3. Bai, G. H., Plattner, R., Desjardins, A., and Kolb, F. L. 2001. Resistance to Fusarium head blight and deoxynivalenol accumulation in wheat. Plant Breed. 120:1-6.

4. Bai, G. H., and Shaner, G. 2004. Management and resistance in wheat and barley to Fusarium head blight. Annu. Rev. Phytopathol. 42:135-161.

5. Bai, G. H., Shaner, G. E., and Ohm, H. W. 2000. Inheritance of resistance to Fusarium graminearum in wheat. Theor. Appl. Genet. 100:1-8.

6. Bourdoncle, W., and Ohm, H. W. 2003. Quantitative trait loci for resistance to Fusarium head blight in recombinant inbred wheat lines from the cross Huapei 57-2/Patterson. Euphytica 131:131-136.

7. Buerstmayr, H., Lemmens, M., Hartl, L., Doldi, L., Steiner, B., Stierschneider, M., and Ruckenbauer, P. 2002. Molecular mapping of QTLs for Fusarium head blight resistance in spring wheat. I. Resistance to fungal spread (type II resistance). Theor. Appl. Genet. 104:84-91.

8. Buerstmayr, H., Steiner, B., Hartl, L., Griesser, M., Angerer, N., Lengauer, D., Miedaner, T., Schneider, B., and Lemmens, M. 2003. Molecular mapping of QTLs for Fusarium head blight resistance in spring wheat. II. Resistance to fungal penetration and spread. Theor. Appl. Genet. 107:503-508.

9. Capettini, F., Rasmusson, D. C., Dill-Macky, R., Schiefelbein, E., and Elakkad, A. 2003. Inheritance of resistance to Fusarium head blight in four populations of Barley. Crop Sci. 43:1960-1966.

10. Gervais, L., Dedryver, F., Morlais, J. Y., Bodusseau, V., Negre, S., Bilous, M., Groos, C., and Trottet, M. 2003. Mapping of quantitative trait loci for field resistance to Fusarium head blight in an European winter wheat. Theor. Appl. Genet. 106:961-970.

11. Gilbert, J., and Tekauz, A. 2000. Review: Recent developments in research on Fusarium head blight of wheat in Canada. Can. J. Plant Pathol. 22:1-8.

12. Grausgruber, H., Lemmens, M., Burstmayr, H., and Ruckenbauer, P. 1999. Resistance of 'Chinese Spring' substitution lines carrying chromosomes from 'Cheyenne', 'Hope' and 'Lutescens 62' wheat to head blight caused by Fusarium culmorum. Hereditas 130:57-63.

13. Groth, J. V., Ozmon, E. A., and Busch, R. H. 1999. Repeatability and relationship of incidence and severity measures of scab of wheat caused by Fusarium graminearum in inoculated nurseries. Plant Dis. 83:10331038.

14. Guyomarc'h, H., Sourdille, P., Edwards, K. J., and Bernard, M. 2002. Studies of the transferability of microsatellite derived from Triticum taushchii to hexaploid wheat and to diploid related species using amplification, hybridization and sequence comparisons. Theor. Appl. Genet. 105:736-744.

15. Johnson, D. D., Flaskerud, G. K., Taylor, R. D., and Satyanarayana, V. 2003. Quantifying economic impacts of Fusarium head blight in wheat.
Pages 461-483 in: Fusarium Head Blight of Wheat and Barley. K. J. Leonard and W. R. Bushnell, eds. The American Phytopathological Society, St. Paul, MN

16. Miedaner, T. 1997. Breeding wheat and rye for resistance to Fusarium diseases. Plant Breed. 116:201-220.

17. Paillard, S., Schnurbusch, T., Tiwari, R., Messmer, M., Winzeler, M., Keller, B., and Schachermayr, G. 2004. QTL analysis of resistance to Fusarium head blight in Swiss winter wheat (Triticum aestivum L.). Theor. Appl. Genet. 109:323-332.

18. Pestsova, E., Ganal, M. W., and Roder, M. S. 2000. Isolation and mapping of microsatellite markers specific for the $\mathrm{D}$ genome of breed wheat. Genome 43:689-697.

19. Röder, M. S., Korzun, V., Wendehake, K., Plaschke, J., Tixier, M. H., Leroy, P., and Ganal, M. W. 1998. A microsatellite map of wheat. Genetics 149:2007-2023.

20. Schmolke, M., Zimmermann, G., Buerstmayr, H., Schwerzer, G., Miedaner, T., Korzun, V., Ebmeyer, E., and Hartl, L. 2005. Molecular mapping of Fusarium head blight resistance in the winter wheat population Dream/Lynx. Theor. Appl. Genet. 111:747-756.

21. Schroeder, H. W., and Christensen, J. J. 1963. Factors affecting resistance of wheat to scab caused by Gibberella zeae. Phytopathology 53:831-838.

22. Shen, X. R., Ittu, M., and Ohm, H. W. 2003. Quantitative trait loci conditioning resistance to Fusarium head blight in wheat line F201R. Crop Sci. 43:850-857.

23. Shen, X. R., Zhou, M., Lu, W., and Ohm, H. 2003. Detection of Fusarium head blight resistance QTL in a wheat population using bulked segregant analysis. Theor. Appl. Genet. 106:1041-1047.

24. Song, Q. J., Shi, J. R., Singh, S., Fickus, E. W., Costa, J. M., Lewis, J., Gill, B. S., Ward, R., and Cregan, P. B. 2005. Development and mapping of microsatellite (SSR) markers in wheat. Theor. Appl. Genet. 110:550560.

25. Somers, D. J., Fedak, G., and Savard, M. 2003. Molecular mapping of novel genes controlling Fusarium head blight resistance and deoxynivalenol accumulation in spring wheat. Genome 46:555-564.

26. Sourdille, P., Cadalen, T., Guyomarc'h, H., Snape, J. W., Perretant, M. R., Charmet, G., Boeuf, C., Bernard, S., and Bernard, M. 2003. An update of the Courtot $\times$ Chinese Spring intervarietal molecular marker linkage map for the QTL detection of agronomic traits in wheat. Theor. Appl. Genet. 106:530-538.

27. Vales, M. I., Schön, C. C., Capettini, F., Chen, X. M., Corey, A. E., Mather, D. E., Mundt, C. C., Richardson, K. L., Sandoval-Islas, J. S., Utz, H. F., and Hayes, P. M. 2005. Effect of population size on the estimation of QTL: A test using resistance to barley stripe rust. Theor. Appl. Genet. 111:1260-1270.

28. Van Ooijen, J. W. 2004. MapQTL 5, Software for mapping of quantitative trait loci in experimental populations. Kyazma B.V., Wageningen, The Netherlands.

29. Van Ooijen, J. W., and Voorrips, R. E. 2001. JoinMap3.0, Software for the calculation of genetic linkage maps. Plant Research International, Wageningen, The Netherlands.

30. Wang, D. R., Zhu, J., Li, Z. K., and Paterson, A. H. 1999. A computer software for mapping quantitative trait loci QTLs with main effects, epistatic effects and QTL environment interactions by mixed linear model approaches. Theor. Appl. Genet. 99:1255-1264.

31. Yang, Z. P., Gibert, J., Fedak, G., and Somoers, D. 2005. Genetic characterization of QTL associated with resistance to Fusarium head blight in a doubled-haploid spring wheat population. Genome 48:187-196.

32. Yao, J. B., Ge, Y. F., Wang, S. W., Yao, G. C., Zhou, C. F., and Qian, C. M. 1997. Chromosomal location of genes for scab resistance in wheat cultivar Sumai 3. Acta Agron. Sin. 23:450-453.

33. Yao, J. B., and Lu, W. Z. 2000. Progress on breeding for wheat scab resistance in China. J. Jiangsu Agric. 16:242-248.

34. Zhang, X., Zhou, M., Ren, L., Bai, G., Ma, H., Scholten, O. E., Guo, P., and Lu, W. 2004. Molecular characterization of Fusarium head blight resistance from wheat cultivar Wangshuibai. Euphytica 139:59-64.

35. Zhou, W. C., Kolb, F. L., Bai, G. H., Domier, L. L., and Yao, J. B. 2002. Effect of individual Sumai 3 chromosomes on resistance to scab spread within spikes and deoxynivalenol accumulation within kernels in wheat. Hereditas 137:81-89.

36. Zhou, W. C., Kolb, F. L., Bai, G. H., Shaner, G. E., and Domier, L. L. 2002. Genetic analysis of scab resistance QTL in wheat with microsatellite and AFLP markers. Genome 45:719-727. 